\title{
ESTRATÉGIA DE PRODUÇÃO EM ARRANJOS PRODUTIVOS CERÂMICOS: $O$ CASO DE PEDREIRA (SP)
}

\section{PRODUCTION STRATEGY OF CERAMIC PRODUCTIVE ARRANGEMENTS: THE EXAMPLE OF PEDREIRA (SP)}

\author{
Daniela Tatiane dos Santos*- dtatiane@dep.ufscar.br \\ Mário Otávio Batalha* dmob@power.ufscar.br \\ * Universidade Federal de São Carlos
}

\begin{abstract}
Resumo: Os Arranjos Produtivos Locais (APLs) possuem importância significativa para atuações cooperadas entre empresas. No entanto, a sua constituição quase sempre revela a ausência de uma estratégia de produção coordenada para as empresas. O modelo de Platts e Gregory (1990), utilizado neste artigo, permite elaborar estratégias conjuntas para empresas, com aplicação em arranjos produtivos. O modelo tem como objetivo articular a integração entre os requisitos do mercado e as competências internas das empresas, identificando aquelas estratégias produtivas possíveis de serem realizadas. Tendo como base o modelo supracitado, este artigo procurou estabelecer estratégias de produção para arranjos produtivos de cerâmica branca, utilizando-se do exemplo de Pedreira (SP). O método de pesquisa foi composto de uma pesquisa empírica realizada em 26 empresas, bem como em uma revisão da literatura sobre estratégias de produção. Os resultados mostraram que, apesar da importância destas práticas, muito pouco se tem feito para a formulação de estratégias de produção conjuntas para empresas e apontam, principalmente, para a elaboração de estratégias baseadas no perfil do cliente a ser atendido e para novos mercados a serem explorados.
\end{abstract}

Palavras-chave: Estratégia de Produção. Modelo Platts e Gregory. Cerâmica Branca. Arranjo Produtivo Local (APL).

\begin{abstract}
The local productive arrangements (LPAs) possess significant importance to the cooperated performance between companies. Meanwhile, their constitution almost reveals the absence of a coordinated production strategy for the companies. The Platts and Gregory (1990)'s model utilized in the present article permits to elaborate joint strategies for companies, with application in productive arrangements. The model intends to articulate the integration between the requirement of the market and the internal competencies of the companies, with the purpose of identifying the production strategies which could be carried out. Basing on the mentioned model, this article aimed at establishing production strategies to white ceramic productive arrangements, utilizing the example of Pedreira, a municipal district of São Paulo state. The research method has uses an empirical study in 26 companies and a review of the literature about production strategies. The results indicated that, despite the importance of these practices, too little has been made for the formulation of joint production strategies for the companies and they point, mainly, towards the elaboration of strategies established on the client profile who will be assisted and new markets which will be explored.
\end{abstract}

Keywords: Production Strategy. Platts and Gregory Model. White Ceramic. Local Produtive Arrangement (LPA). 


\section{INTRODUÇÃO}

Muitos elementos permeiam a formulação de estratégia de produção que vão desde aspectos que remetem à dinâmica da concorrência na indústria às questões mais básicas da resolução de problemas corriqueiros. $O$ alinhamento destes diferentes fatores não é tarefa fácil e impõe grandes desafios aos responsáveis pelas atividades produtivas de pequenas e médias empresas quanto à constituição de estratégias que se sustentam em prazos longos. Este é, sem sombra de dúvida, um ponto que precisa ser mais bem explorado em empresas organizadas em Arranjos Produtivos Locais (APLs) sob a pena de verem destruídos os ganhos associados ao resultado de esforços conjuntos. Ademais, apesar de ser vasta a literatura sobre estes arranjos no Brasil, principalmente no que se refere aos fatores elementares da cooperação entre empresas, muito pouco se discutiu sobre o tema da constituição de estratégias de produção nestes ambientes.

O exemplo de Pedreira (SP) é utilizado neste artigo para ilustrar esta problemática. O município de Pedreira, pólo central do APL estudado, possui 35.219 habitantes. Estima-se que aproximadamente 4.630 pessoas dependam diretamente das atividades relacionadas à produção de cerâmica branca no município, o que corresponde a aproximadamente $13,1 \%$ da população. Este dado aponta a importância do arranjo para a geração de emprego, ainda mais quando se considera que outro grande número de pessoas também depende indiretamente desta atividade.

O setor de cerâmica branca abrange a produção de louça de mesas, refratários e objetos de decoração, sendo que o Instituto Brasileiro de Geografia e Estatística (IBGE) classifica a produção de cerâmica branca dentro da CNAE 26 "Fabricação de Produtos de Minerais Não-Metálicos". A amostra de empresas utilizadas neste trabalho baseou-se em 26 empresas produtoras de cerâmica branca cadastradas na prefeitura do município e no Serviço de Apoio às Micro e Pequenas Empresas (SEBRAE) de São Paulo. Ainda que seja um conjunto relativamente pequeno, este número representa aproximadamente $17 \%$ do total 
de empresas que atualmente produzem louça de mesa e cerâmicas decorativas brancas em Pedreira.

Nos últimos três anos, algumas instituições passaram a promover ações cooperadas no arranjo. A prefeitura iniciou um trabalho com o Serviço Nacional de Aprendizagem Industrial (SENAI) que resultou na inauguração de um laboratório de ensaios em cerâmica branca para o fornecimento de suporte técnico a custos baixos. Mas a busca por melhores padrões de qualidade também pode avançar por meio da realização de um projeto com o Centro de Caracterização e Desenvolvimento de Materiais (CCDM) da Universidade Federal de São Carlos (UFSCar), para o mapeamento dos fatores decisivos e críticos de atuação no mercado cerâmico.

Um dos problemas das pequenas e médias empresas no Brasil, que caracterizam o arranjo que será estudado, é a falta de capacitações e recursos humanos para dominar atividades que se encontram na fronteira do conhecimento e que agregam valor aos produtos e serviços (KOHLS, 2004). Por outro lado, a estruturação das empresas em arranjos produtivos poderia propiciar a conquista de ganhos de competitividade não desprezíveis, através do compartilhamento de recursos entre empresas (CASAROTTO, 1999). Certamente, grandes são os estímulos atuais para que as empresas adotem este tipo de sinergia, em um movimento que, muitas vezes, pretende compensar a inexistência de competências tecnologicamente avançadas. Porém, a inexistência daquelas capacitações geralmente vem acompanhada da ausência de uma estratégia de produção coordenada para as empresas, o que limita de forma significativa, os efeitos dinâmicos das complementaridades realizadas.

Visando avançar nesta discussão, este artigo tem como objetivo mostrar a aplicação de um modelo de elaboração de estratégia de produção que pode auxiliar o desempenho competitivo de empresas situadas em arranjos produtivos locais. Inicialmente, o artigo estrutura-se em uma breve revisão bibliográfica sobre o assunto. Em seguida, são mostrados o método de pesquisa adotado, a aplicação do modelo supracitado e algumas conclusões do trabalho. 


\section{ESTRATÉGIAS DE PRODUÇÃO E O AMBIENTE COMPETITIVO DAS EMPRESAS}

O posicionamento competitivo de uma empresa no mercado é o reflexo de medidas que ela adota para ir ao encontro de características conjunturais e estruturais dos mercados onde atua. Em ambientes com alta intensidade concorrencial, como os setores cerâmicos, o correto estabelecimento de decisões e ações estratégicas por parte das empresas é ainda mais vital do que aquele tomado em ambientes de monopólio ou de oligopólio. Este conjunto de ações ligado à busca de uma posição sustentada no mercado traduz-se nas estratégias corporativas da empresa e, em sentido mais restrito, nas suas estratégias de produção.

Segundo Upton et al (2008), a estratégia de produção pode ser definida como uma seqüência de decisões que possibilita à função produção encontrar objetivos de prazos mais longos, sem desconsiderar aqueles mais cotidianos que possam ter efeitos sobre os primeiros. $O$ trabalho dos autores tem como pano de fundo o reconhecimento da crescente concorrência empresarial e a necessidade das empresas desenvolverem ações e medidas que possibilitem a obtenção de desempenhos superiores aos de seus concorrentes. Uma vez determinada a estratégia de produção é necessário estabelecer um quadro de decisões que devem ser adotadas para atender a demanda do mercado. Estes fatores podem ser classificados como estruturais (instalações industriais, capacidade produtiva, tecnologia e integração vertical) e infra-estruturais (áreas de recursos humanos, gerência da qualidade, organização e planejamento e controle da produção). A base desta abordagem parece basear-se mais diretamente no trabalho de Platts e Gregory (1990), que será explicitado na próxima seção, com a diferença de que este último confere ênfase maior aos requisitos competitivos.

Embora amplamente explorada na bibliografia de estratégias competitivas genéricas, o estabelecimento de prioridades competitivas para uma estratégia de produção baseada em sinais de mercado ainda orientam muitos trabalhos sobre 0 tema. Custos, diferenciação ou focalização tendem a configurar os objetivos estratégicos genéricos das empresas e a caracterizá-las dentro de um mesmo 
setor quanto a sua parcela de mercado ou investimentos em capital (PORTER, 1985). A indústria de cerâmica chinesa, por exemplo, possui uma estratégia clara de produção a baixos custos, com poucos investimentos em qualidade e em diferenciação de produtos. Isto não tem impedido as empresas chinesas de alcançarem melhor posição no mercado internacional do que as brasileiras.

Segundo Prahalad e Hamel (1990), a consolidação de uma prioridade competitiva exige tempo e uma consistente acumulação de competências. Avançando no entendimento das competências empresariais, Andrews (1971) coloca que a estratégia de produção deve compatibilizar as oportunidades advindas do mercado com as capacitações que a empresa possui. $O$ autor enfatiza a necessidade das competências ou recursos orientarem-se pela demanda, sob o risco desta não compatibilização levar à redução dos lucros das empresas. Neste sentido, Slack e Lewis (2001) enfatizam alguns procedimentos básicos para a identificação e formulação de estratégia, centrando-se nos seguintes elementos:

- Integração dos objetivos estratégicos da organização com os recursos disponíveis;

- Compatibilização entre estratégia de produção e estratégia mais geral da empresa;

- Avaliação da importância e desempenho das prioridades competitivas em relação aos consumidores e concorrentes;

- Avaliação das lacunas a serem preenchidas entre o que o mercado exige e desempenho atingido pela operação.

Todos estes elementos podem ser encontrados no âmbito de uma empresa individual. Eles também podem ser considerados no contexto de um setor ou indústria. Mas, com um maior nível de agregação, a elaboração de estratégia deixa de considerar as particularidades de cada empresa e passa a refletir condições mais gerais de competitividade. Avaliação deste procedimento para a definição de estratégias também poderia ocorrer em ambientes de atuação conjunta entre empresas, os chamados arranjos produtivos, onde medidas de 
decisão e implementação de estratégias poderiam ser socializadas entre os agentes do arranjo.

Ainda que um dos objetivos primeiros destes arranjos pareça estar voltado para a coordenação das atividades produtivas dos seus agentes, a definição de estratégias comuns de produção neste tipo de ambiente é quase sempre tomada para um horizonte temporal muito limitado e à revelia de propósitos sistêmicos mais consistentes. Este fato deve-se, parcialmente, aos objetivos distintos que orientam as empresas do arranjo e a conseqüente dificuldade destes serem articulados no longo prazo. Entretanto, a ausência de uma estratégia de produção integrada para as empresas estruturadas em APL contradiz a própria natureza destes arranjos que é o de atuar conjuntamente a fim de se superar obstáculos à sua competitividade e, em última análise, dos agentes que os compõem (LASTRES; SZAPIRO, 2003).

Alguns autores sugerem que as iniciativas de formulação de estratégias de produção no âmbito de APLs deveriam partir de algum agente articulador externo, uma vez que a competição entre empresas pode superar, em muitos casos, as tentativas de cooperação entre elas (FENSTERSEIFER et al, 2000). As cooperações poderiam ser orientadas por estratégias de produção que definissem o tipo de relação que as empresas manterão entre si para obtenção de vantagens competitivas comuns, seja com base nos custos de produção ou em outros objetivos estratégicos. Logo abaixo, será apresentado um modelo teórico de elaboração de estratégias, apropriado e útil quando aplicado em uma ótica de arranjos produtivos.

\subsection{O modelo de Platts e Gregory}

O modelo de Platts e Gregory (1990) destaca três estágios fundamentais para se formular estratégias de produção. Ele realiza uma comparação entre os fatores exigidos pelo mercado e o desempenho da produção, como forma de identificar as estratégias mais adequadas a uma empresa (ver figura 1). 


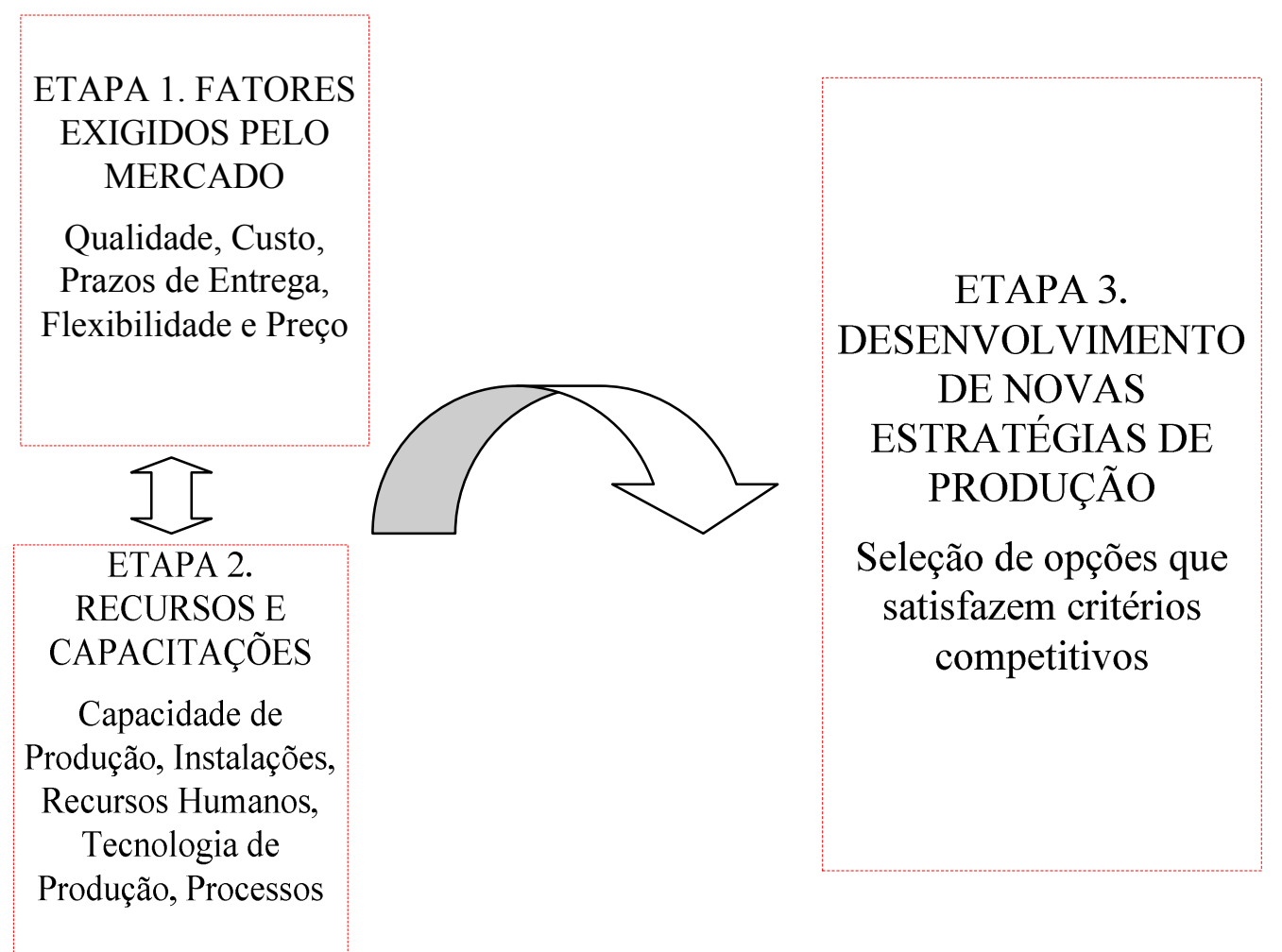

Figura 1: Modelo de Platts e Gregory (1990)

A primeira etapa desenvolve uma compreensão da posição da empresa e dos fatores exigidos pelo mercado. Estes fatores podem ser entendidos em termos de critérios competitivos (qualidade, rapidez, prazos de entrega, flexibilidade e custo) que devem ser priorizados pela função produção, de acordo com os aspectos definidos na estratégia competitiva. É possível classificá-los em termos de fatores ganhadores e qualificadores de pedidos, conforme sugerido por Hill (1993). Os primeiros possibilitam obter diretamente um firme posicionamento competitivo, enquanto os segundos são necessários para a empresa permanecer no mercado. A ênfase nestes requisitos de mercado varia de acordo com as necessidades específicas dos grupos de consumidores, as atividades dos concorrentes e o ciclo de vida dos produtos.

Apesar da existência de trade-offs entre os critérios competitivos, pode-se combiná-los a fim de se obter uma relação equilibrada entre dois ou mais objetivos de desempenho (HILL, 1993). Em alguns negócios, a diferenciação pode não ser incompatível com custos relativamente baixos e com preços comparáveis aos da concorrência. Mas esta conciliação exige que as empresas 
adotem posturas menos conservadoras, não priorizando a escolha de um objetivo singular e explorando as vantagens que podem ser auferidas de opções estratégicas diversas e comuns aos agentes. Neste contexto, pode-se indagar se as escolhas estratégicas das empresas poderiam ser compatibilizadas no âmbito de arranjos produtivos. Embora isto pareça ser teoricamente possível e desejável, Villaschi e Campos (2002) destacam as dificuldades para este tipo de colaboração. Os autores consideram que a competitividade em grande parte dos arranjos produtivos locais no Brasil está lastreada em estratégias conservadoras que buscam reduzir riscos e que dificultam a adoção de apostas mais ousadas pelas empresas pertencentes aos arranjos.

A segunda etapa do modelo avalia as capacitações da produção das empresas. O objetivo é identificar aqueles conhecimentos consolidados que encerram elementos estruturais e infra-estruturais das firmas (capacidade de produção, instalações, recursos humanos, tecnologia de produção e processos) e avaliar a forma pela qual eles podem contribuir para atender os critérios de competição de um dado mercado. As capacitações seriam competências construídas através da combinação de talento gerencial e habilidades e experiência da força de trabalho. Estas competências relacionam-se diretamente aos processos cumulativos de rotinas e aprendizado que permitem à empresa usufruir de algum tipo de vantagem competitiva (PRAHALAD; HAMEL, 1990). Segundo Wheelwright (1984), uma estratégia sólida é responsável pela criação e desenvolvimento de uma série de competências e capacitações que permite à produção se adequar às mudanças no ambiente competitivo.

Por fim, a terceira etapa do modelo teria como resultado a proposição de novas estratégias de produção. Trata-se de identificar as diferentes opções disponíveis para as empresas, tendo em vista os fatores reconhecidos nas etapas anteriores.

\section{MÉTODO DE PESQUISA}

Este trabalho foi dividido em duas etapas principais. A primeira etapa revisou a literatura sobre os elementos constitutivos da formulação de estratégias 
de produção, procurando avançar na compreensão deste processo no âmbito dos APL. A segunda etapa envolveu uma pesquisa empírica, complementar e de apoio à etapa anterior, executada pelos autores por intermédio do $\mathrm{CCDM}^{1}$ situado na UFSCar. Esta pesquisa constitui-se no primeiro levantamento sistemático dos fatores competitivos e necessidades tecnológicas das empresas de cerâmica branca de Pedreira (SP), com o intuito de verificar as estratégias disponíveis para o incremento da competitividade do arranjo.

A pesquisa de campo envolveu 26 empresas de cerâmica branca do município. Os proprietários das empresas responderam a um questionário de perguntas "fechadas" que contemplaram desde a caracterização das suas atividades produtivas e tecnológicas até informações relacionadas ao tema de estratégia de produção. O questionário compunha-se de 28 questões e foi aplicado no decorrer do ano de 2007. O questionário foi aplicado in loco, com os proprietários das empresas. Por se tratar de empresas de pequeno porte, o próprio proprietário era o mais indicado para responder as questões propostas. As entrevistas foram sucedidas por visitas ao chão de fábrica, relevantes para ampliar a compreensão sobre as características dos processos de produção.

Assim, buscou-se apoiar no exemplo de Pedreira para compor estratégias para a atuação de empresas em arranjos cerâmicos, a fim de gerar resultados adequados que propiciem 0 desenvolvimento progressivo de novas competências.

\section{RESULTADOS E DISCUSSÕES}

Esta seção utiliza o esquema teórico do modelo de Platts e Gregory para avaliar as estratégias de produção disponíveis para o arranjo de cerâmica branca de Pedreira. Deste modo, serão descritos os fatores exigidos pelo mercado e as capacitações e recursos presentes nas empresas do arranjo, bem como a

\footnotetext{
${ }^{1}$ O Centro de Caracterização e Desenvolvimento de Materiais (CCDM) é um centro de pesquisa, desenvolvimento e inovação que tem como objetivo executar projetos nas áreas de metais, cerâmicas, polímeros, combustíveis e gestão tecnológica, com o intuito de atender a comunidade acadêmica e industrial.
} 
identificação de algumas estratégias de produção que podem ser utilizadas por elas.

\subsection{A aplicação do modelo}

\subsubsection{Requisitos de mercado para o setor de cerâmica branca}

A produção de cerâmica branca no Brasil está condicionada basicamente por três critérios competitivos que impactam as estratégias de produção das empresas. O primeiro fator está relacionado aos preços praticados no mercado, fator no qual se destaca a concorrência de produtos importados, especialmente os da China. A China é um produtor mundial importante. Ela concentra sua produção na cidade de Nanhai, na província de Guangdong, onde os baixos impostos e a mão-de-obra barata permitem a produção de louça a preços baixos e com custo inferior ao brasileiro. Uma simples visita a um estabelecimento comercial brasileiro do setor basta para comprovar a presença de produtos chineses no mercado brasileiro. $O$ fechamento ou a diminuição da capacidade produtiva de algumas empresas consideradas tradicionais no setor parecem indicar que a indústria brasileira não está conseguindo superar a concorrência dos produtos chineses.

A concorrência dos chineses abrange praticamente todos os produtos fabricados no arranjo de Pedreira: vasos, xícaras, bules, garrafas, porta-retrato, peças de jardim, entre outros. A esta concorrência, somam-se os preços relativamente elevados dos minerais industriais utilizados na produção local de cerâmica, os quais tiveram um forte aumento após a implantação do Plano Real no Brasil. É importante ressaltar que, mesmo adquirindo os insumos minerais dos mesmos fornecedores, algumas cerâmicas pagam mais caro por eles. Este fato deve-se não somente à quantidade quanto à freqüência de compra de matériaprima, sendo que uma empresa que compra com menor freqüência acaba tendo desvantagens devido à baixa escala de aquisição.

O segundo fator que condiciona a estratégia de produção de cerâmica diz respeito à qualidade dos produtos. Por um bom tempo a experiência milenar chinesa em produção cerâmica foi capaz de impor um elevado padrão de 
qualidade aos produtos. Porém, mais recentemente, o amplo conjunto de produtos cerâmicos voltados para a classe $\mathrm{C}$ tem sido uma das principais estratégias dos chineses. Novamente, as empresas de cerâmica branca nacional perderam com o avanço dos chineses em direção a este segmento de mercado, restando-Ihes como alternativa a diferenciação e agregação de valor aos seus produtos. Esta diferenciação depende de fatores que se originam já na aquisição de materiais apropriados indo até as etapas de acabamento. Neste ponto, devese destacar que a qualidade da argila é fundamental para a qualidade e, portanto, para a competitividade dos produtos. A existência de poucos fornecedores nacionais de argilas plásticas para cerâmica branca (ball clays) - argila que oferece alta plasticidade e resistência a seco - é um obstáculo ao desenvolvimento do setor. Este fato é agravado pelo excesso de umidade do material fornecido às cerâmicas. Ademais, a ausência de pesquisa mineral prejudica o trabalho de lavra e de mistura e homogeneização dos lotes de minério, favorecendo variações na qualidade dos lotes de matéria-prima e implicando que muitos problemas de produção somente sejam detectados na fase final de fabricação.

O terceiro fator considerado como critério competitivo na produção de cerâmica são os prazos de entrega dos produtos, uma medida de sua confiabilidade. Este é um elemento que serve para qualificar o produto no mercado através da presença de garantias e redução de falhas de fornecimento. Frente à baixa confiabilidade dos produtos provenientes da China, muito dos quais não se é possível saber a procedência, os produtos nacionais tendem a apresentar um desempenho parcialmente superior neste quesito. Verifica-se, geralmente, um baixo grau de interação entre os elos da cadeia produtiva, quase inexistindo ações cooperadas que busquem maior eficiência coletiva, características amplificadas pela baixa qualificação dos seus fornecedores e canais de distribuição deficientes (GARCIA; SILVA, 2007). Como conseqüência, um aumento da demanda de produtos é dificilmente atendido de imediato. Empresas que conseguem, de algum modo, encontrar esquemas mais confiáveis para a entrega dos produtos acabam por ter vantagens competitivas consideráveis. 
Tendo identificado os fatores críticos no mercado de cerâmica branca, um segundo passo seria identificar o posicionamento do arranjo em relação àqueles critérios. Como foi adotado o caso de Pedreira para exemplificar a aplicação do modelo de Platts e Gregory (1990), serão destacadas as características do desempenho deste arranjo em relação aos fatores críticos de sucesso identificados.

A produção média mensal das empresas de Pedreira é de 2.257.436 produtos, compreendidos entre linha de mesa e decorativa, divididas em porcelanas e faianças. Estima-se que este número representa aproximadamente $20 \%$ do total de cerâmicas branca de decoração e de mesa atualmente produzidas no país. Trata-se de pequenas e médias empresas com faturamento médio mensal em torno de $\mathrm{R} \$ 50$ mil que empregam, em média, 16 funcionários alocados em diferentes atividades. As empresas do APL possuem predominantemente uma estrutura organizacional bastante simples, com o proprietário assumindo o papel concentrador de todas as decisões e métodos de produção e gestão convencionais.

A definição do preço dos produtos vendidos é o ponto mais conflituoso entre os agentes do arranjo. Ele representa um obstáculo importante para 0 estabelecimento de ações cooperadas, uma vez que existem poucos acordos quanto ao preço a ser praticado dentro do arranjo. Além disso, os agentes produtivos do APL desconhecem os preços dos concorrentes em regiões mais distantes, o que dificulta ainda mais o estabelecimento de estratégias comuns de precificação. Esta falta de conhecimento indica o baixo nível de expectativa dos empresários sobre a comercialização de seus produtos fora da região. As principais cidades de destino dos produtos são aquelas situadas no interior de São Paulo. A divulgação de produtos possui um papel central na comercialização de produtos, um dos principais instrumentos no processo de concorrência. Observa-se, no entanto, que as atividades dedicadas à realização de marketing e propaganda são incipientes, uma vez que não são realizados esforços duradouros na divulgação de seus produtos. Isto limita a obtenção de novos clientes em outras regiões do Brasil e aponta para a possibilidade da adoção de uma estratégia conjunta para a comercialização e para os preços praticados. 
Uma análise das matérias-primas e insumos utilizados no processo produtivo serve para indicar alguns caminhos para o aumento da competitividade das empresas do APL. A produção de cerâmica branca ocorre por meio da formulação de uma massa, geralmente, composta de 16\% de argila, 34\% feldspato, $33 \%$ de caulim e $17 \%$ de quartzo, porcentagens que são consideradas sigilosas pelos empresários, pois esconderiam "a poção mágica que dá vida à massa bruta". Além disso, nesta produção são utilizados alguns fundentes como a dolomita, o filito e o óxido de ferro que conferem insolubilidade à mistura, com aplicação na fabricação de faianças. Na medida em que admitem tonalidades mais escuras podem ser agregadas matérias-primas fundentes "mais impuras", de maior disponibilidade e mais baratas que o feldspato, como o filito e o granito. Quando interrogados sobre o custo de aquisição dos materiais e insumos, a maioria dos empresários fez ressalvas quanto ao custo dos silicatos e da argila.

Os silicatos são, quando considerados os seus preços de mercado, as matérias-primas mais caras do processo, mas a quantidade consumida na produção é bastante pequena, não sendo crítica para o custo total destas empresas. O gás liquefeito do petróleo (GLP) também poderia ser destacado como crítico, representando uma cifra de $11 \%$ dos custos de produção. No entanto, a argila ocupa uma porcentagem sobre o custo total bem mais modesta do que o teriam o caulim e o feldspato, com volumes de consumo mais elevados. Logicamente, que isto sinaliza para a necessidade de maior conhecimento dos custos efetivos dos componentes e do seu impacto sobre a formação de preços. É admissível que pouco se saiba sobre o quase desconhecido processo de formação de preços dos produtos chineses. Porém, estratégias de mercado mais eficientes para as empresas brasileiras poderiam ser estabelecidas a partir do conhecimento mínimo dos seus custos de produção. Infelizmente, estes são dados ainda não calculados pelas empresas, o que coloca obstáculos à definição e mensuração de impactos das estratégias de produção atuais ou potenciais. Assim, apesar da implantação de estratégias de produção de redução de custos ser relativamente óbvia como forma de aumentar a competitividade do setor, especialmente frente aos concorrentes chineses, ela esbarra na falta de 
informações que auxiliem no estabelecimento e avaliação de eventuais mudanças nas políticas de produção.

Outra opção estratégica a ser ensejada seria a de competir com produtos de maior qualidade técnica. As matérias-primas utilizadas pelos agentes do arranjo estudado foram consideradas pelos entrevistados como de boa qualidade, com exceção da argila, cuja umidade teve épocas que se situou na faixa de 35 a $40 \%$. A dependência de poucas mineradoras - 38\% das empresas entrevistadas nunca realizaram nenhum tipo de atividade de prospecção de novas matériasprimas - é explicada pela indisponibilidade no solo brasileiro de argilas plásticas de boa qualidade para cerâmica branca (MENEZES et al, 2003). Mas, estes problemas não deveriam impedir as empresas do APL de buscarem melhorias de processo e produto via utilização de novas estratégias de produção. Ainda são poucas as empresas do arranjo que realizam mudanças no processo produtivo. Entre estas, destacam-se aquelas que, no período compreendido entre 2004 a 2007 , adquiriram novas máquinas e equipamentos (27\%) e novos processos que minimizaram o uso de matéria-prima (15\%).

Por outro lado, existe uma tentativa entre as empresas de padronizar a qualidade do processo produtivo. Este empenho se deve principalmente a um laboratório em cerâmica inaugurado recentemente e que envolve esforços da prefeitura de Pedreira e do SENAI. Este laboratório tem permitido as empresas aprenderem novas técnicas de produção e utilizarem ensaios para o controle das dimensões antes e depois da queima e análise da densidade da massa. Convém destacar que em $88,5 \%$ das empresas o controle da qualidade do produto é puramente visual, não sendo utilizados ensaios técnicos que avaliem a qualidade da matéria-prima ou do processo produtivo. Entretanto, testes por amostragem e medição da temperatura do forno vêm sendo realizados por $42,3 \%$ e $80,8 \%$ das empresas, respectivamente. Este é certamente um primeiro passo rumo à obtenção de produtos com maior valor agregado e de melhor qualidade. Estratégias de diferenciação de produtos a jusante da cadeia de produção, que resultem no acesso a canais de distribuição ligados a consumidores mais exigentes, demandam contínuos e intensos esforços em qualidade de processo, produto e gestão. Em outras palavras, se os concorrentes internacionais parecem 
ter como vantagens competitivas os seus custos e preços de venda, uma das estratégias a serem seguidas seria a de diferenciação de produtos. Esta estratégia seria facilitada pela proximidade maior entre o produtor e o consumidor nacional. Para isso, são vitais os investimentos em qualidade e em técnicas de gestão mais modernas.

Em relação à entrega dos produtos, o estabelecimento de algumas ações coletivas derivadas desta opção estratégica parece ser rapidamente passível de implantação. Embora se verifique pontos de tensão entre os elos da cadeia de produção, são nítidas as intenções das empresas de abandonarem práticas de relacionamentos individualizados junto aos seus fornecedores. Aproximadamente 92\% das empresas têm interesse em participar da compra conjunta de matériaprima para a produção de cerâmica branca. O gráfico 1 mostra que, em 2007, dentre as matérias-primas que as empresas tinham interesse em adquirir em conjunto destacaram-se a argila (81\%) e o caulim (69\%). Práticas desta natureza trazem vantagens inquestionáveis do ponto de vista de diminuição de custos de aquisição e de aumento do poder de barganha das empresas por matérias-primas de melhor qualidade.

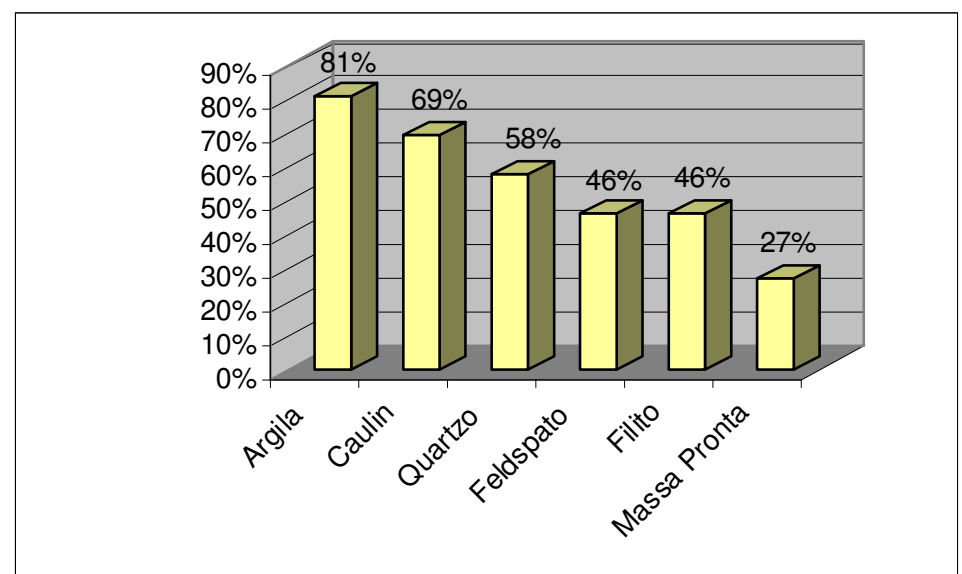

Gráfico 1: Matérias-Primas que as Empresas possuem Interesse em Adquirir Conjuntamente (\%) Fonte: Pesquisa de campo

Assim, a compra conjunta por intermédio de uma central de matéria-prima seria um importante instrumento para aumentar o poder de barganha das pequenas empresas de Pedreira junto aos seus fornecedores. Esta central poderia propiciar melhor negociação com fornecedores e conseqüentes reduções 
no preço de compra de matérias-primas. Um pré-requisito para este comprometimento mútuo entre as empresas do arranjo seria a adaptação das diferentes necessidades de compras, em termos de qualidade e quantidade, limitando a tomada de decisões individuais.

A organização de empresas em arranjos produtivos locais promove a competitividade destas empresas por meio da obtenção de economias de aglomeração, permitindo reduzir trade-offs presentes na manufatura e procurando balancear objetivos diversos. Entretanto, considerando-se uma ordem de importância e de possibilidade de implantação crescentes, estratégias de diminuição de custos, entrega dos produtos e qualidade seriam, respectivamente, as alternativas que as empresas do arranjo poderiam adotar para fugir daqueles caminhos já amplamente trilhados pela concorrência internacional.

\section{Etapa 2 - Identificação dos recursos e capacitações do arranjo}

A utilização do modelo de Platts e Gregory (1990) permitiu identificar dois grupos de recursos e capacitações relacionados ao conhecimento existente no arranjo que devem ser dimensionados para atender os critérios competitivos acima mencionados. O primeiro fator que pode ser destacado é o processo produtivo, praticamente o mesmo para todas as empresas. Na fabricação de cerâmica branca as matérias-primas são primeiramente homogeneizadas nos moinhos rotativos onde se produz uma massa pastosa. Esta massa é prensada para a retirada de água e passada por extrusão nas marombas, retirando-se o ar quando o objetivo é produzir xícaras, isoladores, entre outros. A massa pode ainda ser colocada em formas de gesso para que a água seja absorvida e adquira a forma desejada. Depois de alguns minutos, as peças são colocadas para secarem em temperatura ambiente, antes de serem esmaltadas para uma présecagem. Logo após, as peças passam para o acabamento, esmaltação e queima em fornos elétricos ou a gás liquefeito do petróleo.

Pode-se notar que não é exigida uma base de conhecimento complexa para este tipo de processo de produção. O principal ponto que necessitaria ser considerado como eventual fonte de melhorias do processo refere-se às 
máquinas e equipamentos das empresas. Em 2007, as empresas do arranjo possuíam, em conjunto, 101 moinhos e 58 fornos, com variações em dimensão e capacidade de produção. A maior parte destes equipamentos está defasada tecnologicamente, sendo que o processo de moagem é, na maioria dos casos, controlado somente de forma visual. Grande parte das empresas não possui caminhão e outros equipamentos de transporte, sendo que o pagamento de frete é o meio utilizado por elas para obterem as matérias-primas e insumos e transportar o produto acabado. Na formulação de estratégia para o arranjo é importante reconhecer que, embora o processo de produção não seja tecnologicamente dinâmico, a adequação da tecnologia de produção permitiria reduzir custos de manutenção de equipamentos e reforçar diretamente aquelas estratégias de competição em preços e qualidade.

Recursos humanos seria o segundo elemento cuja base de conhecimento exige dimensionamento. A tabela 1 mostra que as 26 empresas possuíam 464 funcionários em 2007. Aproximadamente $88 \%$ destes funcionários possuem o ensino básico ( $5^{\underline{a}}-8^{\underline{a}}$ séries), sendo que somente $5,2 \%$ possuem algum tipo de curso superior.

Tabela 1: Qualificação da Mão-de-Obra

\begin{tabular}{l|c|c}
\hline \multicolumn{1}{c|}{ Nível } & $\begin{array}{c}\text { Número de } \\
\text { funcionários em } \\
\mathbf{2 0 0 7}\end{array}$ & $\%$ \\
Não alfabetizado & 6 & $1,3 \%$ \\
$1^{\mathrm{a}}-4^{\mathrm{a}}$ - séries & 116 & $25,0 \%$ \\
$5^{\mathrm{a}}-8^{\mathrm{a}}$ séries & 252 & $54,3 \%$ \\
$2^{0} \mathrm{Grau}$ & 41 & $8,8 \%$ \\
Técnico & 26 & $5,6 \%$ \\
Superior & 24 & $5,2 \%$ \\
Total & $\mathbf{4 6 4}$ & $\mathbf{1 0 0 , 0 \%}$ \\
\hline
\end{tabular}

Fonte: Pesquisa de campo.

Os empresários consultados consideram que a experiência do trabalhador é o principal fator responsável pela qualidade na produção de cerâmica branca. Ao mesmo tempo $85 \%$ deles afirmaram que o desempenho atual dos trabalhadores é apenas regular. Esta constatação assinala a importância do desenvolvimento de cursos de aperfeiçoamento e formação para esta mão-deobra. No entanto, embora $30,4 \%$ das empresas relatem que seus funcionários 
participam de treinamentos oferecidos por terceiros, estes treinamentos são geralmente oferecidos para os próprios proprietários e não para o conjunto de mão-de-obra da empresa. A maioria dos funcionários das cerâmicas nunca participou de treinamentos que permitissem melhorar a eficiência de seu trabalho, prevalecendo o treinamento interno onde os mais experientes capacitam os menos experientes. A obtenção de melhores qualificações para os trabalhadores quase sempre se traduz em melhorias de qualidade e produtividade do trabalho.

Por outro lado, a "cultura do planejamento" ainda é incipiente nas empresas do arranjo. A grande maioria das empresas de Pedreira não possui um planejamento para a execução de suas atividades. O caráter imediatista das ações e decisões pode ser verificado pelo fato de $77 \%$ das empresas realizarem planejamento para o curto prazo, geralmente para uma semana. A visão estratégica do negócio é uma ferramenta que necessita ser desenvolvida de modo que o proprietário reconheça sua empresa como um negócio, não simplesmente como seu meio de subsistência. Um dos reflexos da implantação de ferramentas de planejamento seria a possibilidade de realizar programações que considerassem a capacidade produtiva da empresa e as demandas do mercado. Reflexos positivos do planejamento poderiam ser sentidos nas etapas a montante e a jusante da cadeia de produção, o que favoreceria a consolidação daquelas estratégias com enfoque na entrega dos produtos.

Deste modo, o processo produtivo e os recursos humanos são os elementos centrais que melhor caracterizam o conjunto de recursos e capacitações peculiares à produção de cerâmica branca. Isto deve-se às especificidades deste sistema de produção e sua alta dependência da experiência do trabalhador.

\section{Etapa 3 - Desenvolvimento de novas estratégias de produção}

Seria possível argumentar que em virtude do porte reduzido e das características do mercado, poucos espaços se abririam para a formulação de novas estratégias para as empresas do arranjo. No entanto, é justamente a escala de produção reduzida, além dos outros problemas já mencionados, que 
acentuam a importância de estratégias comuns e inovadoras para estas empresas.

Como exposto nas etapas anteriores, as opções estratégicas disponíveis para o APL de Pedreira fazem menção ao desenvolvimento de medidas que priorizem esforços em preços, entrega dos produtos e, principalmente, qualidade. Entretanto, o êxito de qualquer medida dependerá do conjunto de conhecimentos presentes no arranjo, em grande parte, das características do processo de produção e recursos humanos. Assim, os resultados da pesquisa apontam para três estratégias centrais, ambas apoiadas em mecanismos de diversificação para o arranjo: constituição de uma central de massas, identificação de novos perfis de cliente e busca de novos mercados.

A constituição de uma central de massas que homogeneíze as misturas da argila possibilitaria melhorias para os produtos fabricados, bem como 0 compartilhamento de custos entre os empresários. Certamente, uma central de utilização conjunta teria o efeito de baratear os preços e ampliar a qualidade dos produtos. Por outro lado, os principais clientes das empresas são as lojas de decoração e de material de construção. Este tipo de comercialização torna as empresas do arranjo reféns de um mercado relativamente restrito. Seria importante, no entanto, a adoção de uma estratégia de produção que favorecesse a identificação de diferentes clientes a serem atendidos, principalmente em mercados pouco explorados pelas empresas, como por exemplo, o da região Nordeste. As empresas do arranjo poderiam direcionar suas vendas ao turismo daquela região, criando produtos direcionados aos visitantes do comércio local.

Entretanto, em quase todas as empresas, o enfoque em preços é muitas vezes preferível à ênfase em qualidade, conquanto concorrer em preços seja um caminho mais difícil a ser seguido devido às barreiras impostas pela concorrência chinesa. Por outro lado, existe uma grande concorrência entre as empresas do próprio arranjo. Isto deve-se, em grande parte, ao fato de os produtos destas empresas serem pouco diferenciados entre si. Assim, o mais conveniente seria buscar diferenciar os produtos (por exemplo, design ou pintura variados) como forma de atingir segmentos de classe $A$ ou $B$ aonde as características apelativas de preços baixos possuem muito menos força. Em outras palavras, a tentativa de 
atuação no mercado se daria com baixo e médio volume de produção, alta variedade e qualidade.

\section{CONCLUSÕES}

Este trabalho teve o intuito de mostrar a aplicação de um modelo de formulação de estratégia que levasse ao aumento do desempenho competitivo de empresas constituídas em arranjos produtivos baseados em produtos cerâmicos. O modelo foi aplicado ao arranjo produtivo local de cerâmica branca de Pedreira. Os resultados da aplicação revelam problemas que são comuns a estes tipos de ambientes produtivos, entre os quais destacam-se a falta de conhecimento sobre as demandas de mercado e a ausência de instrumentos gerenciais capazes de avaliar e propor melhorias que levem ao aumento do desempenho da produção. Isto remete a uma questão adjacente à constituição de estratégias que deve ser ao menos mencionada e que parece condicionar o sucesso destes empreendimentos que é a necessidade dos agentes mais engajados com a constituição do arranjo possuir perfil empreendedor.

O modelo teórico foi capaz de contribuir para a formulação de estratégias para o APL de cerâmica branca de Pedreira. As três principais estratégias identificadas e que estariam disponíveis para as empresas estariam centradas na identificação de novos perfis de cliente (diferenciação) via uma melhor segmentação do mercado, a constituição de uma central de massas e a busca de novos mercados (diversificação). Estas estratégias foram delineadas considerando-se os requisitos do mercado e as capacitações e recursos das empresas. Em virtude da elevada concorrência chinesa, caracterizada pelos baixos preços dos produtos, as estratégias que poderiam ser adotadas pelo arranjo estão ligadas com a diversificação de mercados ou diferenciação de produtos. Neste sentido, esforços estratégicos em qualidade voltados para processos, produtos e gestão poderiam ter um elevado grau de importância para a superação dos muitos entraves concorrenciais que as empresas deste APL enfrentam. 
A coordenação para a elaboração e implementação de estratégias de produção das empresas de arranjos de cerâmica branca deveria enfocar, principalmente, melhorias qualitativas, ainda que seja relevante a concentração de esforços em preços e entrega de produtos. Certamente, a opção estratégica em qualidade contribui para a obtenção de custos e preços baixos para os produtos, embora exija a adoção de posturas menos conservadoras quanto aos objetivos a serem priorizados.

\section{REFERÊNCIAS}

ANDREWS, K. R. The concept of corporate strategy. New York: Dow JonesIrwin, 1971.

CASAROTTO FILHO, N.; PIRES, L. H. Redes de pequenas e médias empresas e desenvolvimento local: estratégias para a conquista da competitividade global com base na experiência italiana. São Paulo: Atlas, 1999.

FENSTERSEIFER, J. E. et al. Internacionalização e cooperação: dois imperativos para a empresa do terceiro milênio. Revista Eletrônica de Administração, n. 3, v. 6,2000 .

GARCIA, R.; SILVA, G. S. Cerâmica revestimentos: relatório setorial final DPP/FINEP, 2007. Disponível em: <www.finep.gov.br/portaldpp >. Acesso em: 30 out. 2007.

HILL, T. Manufacturing strategy. Londres: Macmillian, 1993.

KOHLS, V. K. As ênfases estratégicas de empresas agroalimentares: estudo de casos na região de Pelotas-RS. 2004. 238p. Tese (Doutorado em Administração) - Escola de Administração, Universidade Federal do Rio Grande do Sul, Porto Alegre, 2004.

LASTRES, H.; SZAPIRO, M. Novas políticas na era do conhecimento: o foco em arranjos produtivos e inovativos locais. Universidade Federal do Rio de Janeiro, 2003.

MENEZES, R. R. et al. Caracterização de argilas plásticas do tipo ball clay do litoral paraibano. Cerâmica, v. 49, n. 311, 2003.

PLATTS, K. W.; GREGORY, M. J. Manufacturing audit in the process of strategy formulation. International Journal of Operations and Production Management, v. 10 , n. $9,1990$. 
PORTER, M. E. Competitive advantage. New York: The Free Press, 1985.

PRAHALAD, C. K.; HAMEL, G. The core competence of the corporation. Harvard Business Review, mai-jun., 1990.

SLACK, N.; LEWIS, M. Operations strategy. New Jersey: Prentice Hall, 2001. SOUZA, S. F. A indústria cerâmica de Pedreira e seus impactos ambientais: subsídios para uma gestão ambiental pública. 2003. 117 p. Dissertação (Mestrado em Geociências) - Instituto de Geociências, Universidade de Campinas, Campinas, 2003.

UPTON, D.; HAYES, R.; PISANO, G. Produção, estratégia e tecnologia: em busca da vantagem competitiva. São Paulo: Artmed, 2008.

VILLASCHI, A.; CAMPOS, R. Arranjos e sistemas produtivos locais e políticas para uma economia do conhecimento e do aprendizado. Nota Técnica 3.2.

Contrato BNDES/FINEP/FUJB, Rio de Janeiro. Instituto de Economia, Universidade Federal do Rio de Janeiro, 2000.

WHEELWRIGHT, S. C. Manufacturing strategy: defining the missing link. Strategy Management Journal, v. 5, 1984.

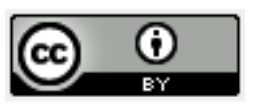

Artigo recebido em 13/07/2009 e aceito para publicação em 18/05/2010. 